Support statement: L. Tan is supported by the Cambridge National Institute for Health Research (NIHR) Biomedical Research Centre; J.A. Dickens is a Medical Research Council (MRC) clinical training fellow and recipient of a Sackler Studentship; D.L. DeMeo was supported by a Doris Duke Clinical Scientist Career Development Award; S.J. Marciniak is a MRC senior clinical fellow; and I. Haq is supported by GlaxoSmithKline. This work was funded by the MRC (UK) and the NIHR University College London Hospital Biomedical Research Centre.

Conflict of interest: Disclosures can be found alongside the online version of this article at www.erj.ersjournals.com

Acknowledgements: The authors would like to thank all the participants in the $\alpha_{1}$-Antitrypsin Genetic Modifier Study for their enthusiastic support and participation. We would also like to thank E. Silverman (Boston, MA, USA) for his comments on the manuscript and R. Crapo (Salt Lake City, UT, USA) for his review and quality assurance of a subset of the spirometry data.

\title{
References
}

Lomas DA, Evans DL, Finch JT, et al. The mechanism of $\mathrm{Z} \alpha_{1}$-antitrypsin accumulation in the liver. Nature 1992; 357: 605-607.

2 Alam S, Li Z, Janciauskiene S, et al. Oxidation of $\mathrm{Z} \alpha_{1}$-antitrypsin by cigarette smoke induces polymerization: a novel mechanism of early-onset emphysema. Am J Respir Cell Mol Biol 2011; 45: 261-269.

3 Gross B, Grebe M, Wencker $M$, et al. New findings in PiZZ $\alpha_{1}$-antitrypsin deficiency-related panniculitis. Demonstration of skin polymers and high dosing requirements of intravenous augmentation therapy. Dermatology 2009; 218: 370-375.

4 Morris $\mathrm{H}$, Morgan MD, Wood AM, et al. ANCA-associated vasculitis is linked to carriage of the Z allele of $\alpha_{1}$ antitrypsin and its polymers. Ann Rheum Dis 2011; 70: 1851-1856.

5 Miranda E, Pérez J, Ekeowa UI, et al. A novel monoclonal antibody to characterize pathogenic polymers in liver disease associated with $\alpha_{1}$-antitrypsin deficiency. Hepatology 2010; 52: 1078-1088.

6 DeMeo DL, Sandhaus RA, Barker AF, et al. Determinants of airflow obstruction in severe $\alpha_{1}$-antitrypsin deficiency. Thorax 2007; 62: 806-813.

7 Mulgrew AT, Taggart CC, Lawless MW, et al. Z $\alpha_{1}$-antitrypsin polymerizes in the lung and acts as a neutrophil chemoattractant. Chest 2004; 125: 1952-1957.

8 Lomas DA, Elliott PR, Sidhar SK, et al. $\alpha_{1}$-antitrypsin Mmalton ( $\mathrm{Phe}^{52}$-deleted) forms loop-sheet polymers in vivo: evidence for the C sheet mechanism of polymerisation. J Biol Chem 1995; 270: 16864-16870.

9 Elliott PR, Stein PE, Bilton D, et al. Structural explanation for the deficiency of S $\alpha_{1}$-antitrypsin. Nat Struct Biol 1996; 3: 910-911.

10 Mallya M, Phillips RL, Saldanha SA, et al. Small molecules block the polymerization of $\mathrm{Z} \alpha_{1}$-antitrypsin and increase the clearance of intracellular aggregates. J Med Chem 2007; 50: 5357-5363.

\section{Impact of theophylline/corticosteroid combination therapy on sputum hydrogen sulfide levels in patients with COPD}

To the Editor:

Hydrogen sulfide $\left(\mathrm{H}_{2} \mathrm{~S}\right)$ has emerged as a new and important endogenous regulator of inflammation in recent years [1] and may also protect from emphysema induced by cigarette smoke exposure [2]. We have also recently shown that $\mathrm{H}_{2} \mathrm{~S}$ can inhibit airway smooth muscle cell proliferation and inflammatory mediator release in vitro [3]. Serum levels of $\mathrm{H}_{2} \mathrm{~S}$ positively correlate with the decline in lung function in chronic obstructive pulmonary disease (COPD) and were significantly lower in Global Initiative for Chronic Obstructive Lung Disease (GOLD) stage III patients compared with those in GOLD I [4]. Existing therapies for COPD, such as corticosteroids or long-acting anticholinergic agents, may reduce the exacerbation rate but do not significantly slow disease progression. A previous study has shown that theophylline alone had no impact on serum $\mathrm{H}_{2} \mathrm{~S}$ levels and is of limited value in the management of stable COPD [5]. Interestingly, sputum $\mathrm{H}_{2} \mathrm{~S}$ measured in patients with asthma correlated with sputum neutrophil counts and the degree of airflow obstruction measured by forced expiratory volume in $1 \mathrm{~s}$ (FEV1) \% predicted [6]. Moreover, combination therapy of an inhaled glucocorticoid with low-dose theophylline has been shown to attenuate airway inflammation in patients with COPD and reverse glucocorticoid resistance [7]. We therefore investigated whether the combination of inhaled corticosteroid and low-dose theophylline, as opposed to low-dose theophylline alone, would modulate $\mathrm{H}_{2} \mathrm{~S}$ levels in the lungs of COPD patients. We now report the levels of $\mathrm{H}_{2} \mathrm{~S}$ assayed in sputum samples collected during this study (www.clinicaltrials.gov identifier NCT00241631), details of which have already been published [7]. 

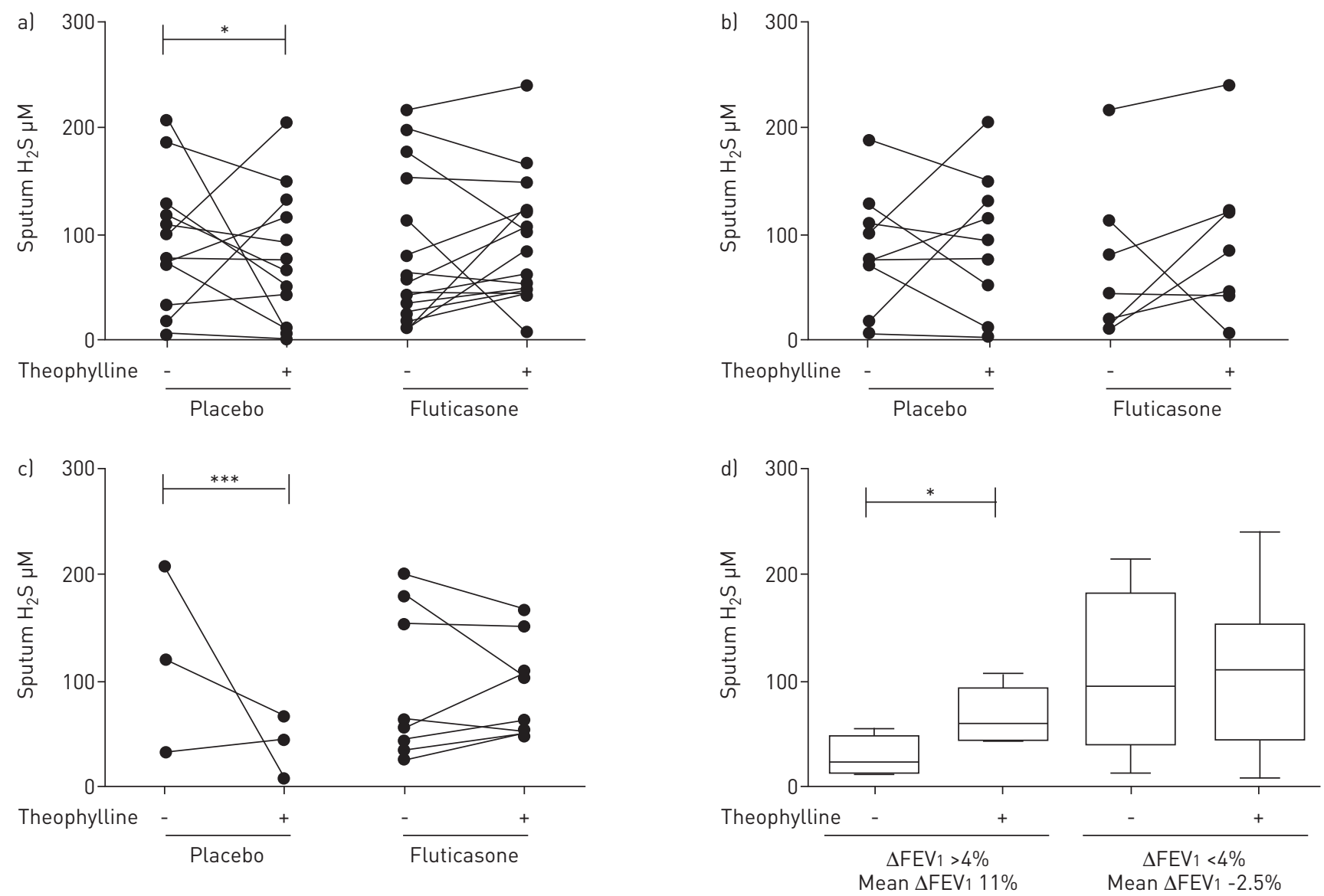

FIGURE 1 The impact of low-dose theophylline alone or in combination with inhaled fluticasone on sputum hydrogen sulfide $\left(\mathrm{H}_{2} \mathrm{~S}\right)$ levels a) in all chronic obstructive pulmonary disease (COPD) subjects, b) only in Global Initiative for Chronic Obstructive Lung Disease (GOLD) stage II COPD subjects, c) only in GOLD III COPD subjects and d) in all COPD patients stratified according to the degree of improvement in forced expiratory volume in $1 \mathrm{~s}(\Delta \mathrm{FEV} 1)$ following theophylline/fluticasone combination therapy. Data are shown for the baseline visit (no theophylline) versus the final visit (after theophylline administration) and displayed either as $\mathrm{a}-\mathrm{c}$ ) paired data between the two visits for each subject in each arm of the study (placebo versus fluticasone) or $\mathrm{d}$ ) the mean in a box and whisker plot for the fluticasone arm of the study only. ${ }^{*}: \mathrm{p}<0.05 ;{ }^{* * *}: \mathrm{p}<0.001$.

Briefly, a total of 29 patients with stable COPD, 18 in GOLD II and 11 in GOLD III, provided sputum for the measurement of $\mathrm{H}_{2} \mathrm{~S}$. After an initial 2-week washout during which all inhaled corticosteroid was ceased, subjects were randomised into two treatment arms, one with inhaled fluticasone propionate ( $500 \mathrm{mg}$ twice daily) the other without for 4 weeks; both arms were given placebo theophylline capsules. After another 2-week washout period, this was followed by a further 4-week period where both arms were given active slow-release theophylline capsules (250 mg twice daily). Induced sputum samples were obtained at the end of the initial run-in period and at the end of each 4-week treatment period. The supernatant fraction was analysed for $\mathrm{H}_{2} \mathrm{~S}$ content using a method that accounts for all $\mathrm{H}_{2} \mathrm{~S}$ species and those derived from it at physiological $\mathrm{pH}$, as described previously [8]. The data were analysed using the statistical package SPSS (version 8; IBM, Armonk, NY, USA) incorporating mixed models to account for nonconstant variability across visits and correlation between visits within patient groups. Over the course of the study, COPD subjects as a group exhibited a significant decrease in sputum $\mathrm{H}_{2} \mathrm{~S}$ levels in the placebo arm compared with the fluticasone propionate arms (fig. 1a). When patients were analysed according to disease severity, as defined by GOLD status, those patents in GOLD II showed no change in sputum $\mathrm{H}_{2} \mathrm{~S}$ levels in either the placebo or fluticasone arms (fig. 1b). As a group, GOLD III COPD subjects in the placebo arm (no fluticasone) had a reduced level of sputum $\mathrm{H}_{2} \mathrm{~S}$ after 4 weeks treatment with theophylline only compared with baseline (fig. 1c). In contrast, GOLD III subjects as a group in the fluticasone arm exhibited no changes in sputum $\mathrm{H}_{2} \mathrm{~S}$ levels after theophylline treatment (fig. 1c). Interestingly, when sputum $\mathrm{H}_{2} \mathrm{~S}$ levels were analysed within the context of changes in FEV1, those COPD patients who exhibited the greatest increase in FEV1 upon the addition of theophylline to fluticasone had very low initial sputum $\mathrm{H}_{2} \mathrm{~S}$ levels. $\mathrm{H}_{2} \mathrm{~S}$ levels rose significantly for all subjects in this subgroup upon addition of theophylline to 
fluticasone (fig. 1d). This effect was not apparent in either the placebo arm of the study or those subjects in the fluticasone arm that had an elevated baseline $\mathrm{H}_{2} \mathrm{~S}$ level.

The significance of decreased sputum $\mathrm{H}_{2} \mathrm{~S}$ levels in GOLD III is not clear. It may simply reflect the greater degree of oxidative burden in the GOLD III COPD lung [9] as $\mathrm{H}_{2} \mathrm{~S}$, or species derived from it at physiological $\mathrm{pH}$, readily interacts with detrimental oxidant species, such as nitric oxide, peroxynitrite and hypohalous acids. Alternatively, as corticosteroids appear to induce the synthesis of endogenous $\mathrm{H}_{2} \mathrm{~S}$ synthesis enzymes [10], our results may simply reflect a lower level of endogenous $\mathrm{H}_{2} \mathrm{~S}$ in more severe COPD in the absence of corticosteroid. The most surprising finding was that those subjects in the fluticasone study arm who had low baseline levels of sputum $\mathrm{H}_{2} \mathrm{~S}$ demonstrated the greatest increase in FEV1 upon the addition of theophylline. This suggests that low sputum $\mathrm{H}_{2} \mathrm{~S}$ levels could act as a biomarker for those COPD subjects who could benefit the most from theophylline/corticosteroid combination therapy. Clearly, this small study is hypothesis generating, requires replication and should be interpreted with great caution. However, our data confirm previous evidence suggesting that theophylline alone does not regulate $\mathrm{H}_{2} \mathrm{~S}$ levels [5] and also suggest that the combination of theophylline plus fluticasone at least maintains $\mathrm{H}_{2} \mathrm{~S}$ levels in patients with GOLD II or III disease. Increased $\mathrm{H}_{2} \mathrm{~S}$ levels in the fluticasone arm may be due to increased expression of $\mathrm{H}_{2} \mathrm{~S}$-synthesising enzymes [10]. This effect would be independent of the transrepression actions associated with loss of histone deacetylase 2 [9] and may suggest that transactivation by corticosteroids is unaffected in COPD. In conclusion, monotherapy with theophylline does not appear to have any impact on maintaining or further increasing sputum $\mathrm{H}_{2} \mathrm{~S}$ levels. In combination with inhaled corticosteroid, however, while there is a trend towards increasing sputum $\mathrm{H}_{2} \mathrm{~S}$ levels, this is most evident in those COPD subjects who had very low baseline sputum $\mathrm{H}_{2} \mathrm{~S}$ levels and, furthermore, appeared to benefit most in relation to increases in FEV1.

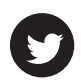

@ERSpublications

COPD patients with low airway $\mathrm{H}_{2} \mathrm{~S}$ benefit from theophylline/corticosteroid therapy with increased FEV1 and $\mathrm{H}_{2} \mathrm{~S}$ levels http://ow.ly/sx2u4

Paul A. Kirkham ${ }^{1,2}$, Matthew Whiteman ${ }^{3}$, Paul G. Winyard ${ }^{3}$, Gaetano Caramori ${ }^{4}$, Fabiana Gordon ${ }^{5}$, Paul A. Ford ${ }^{1}$, Peter J. Barnes ${ }^{1}$, Ian M. Adcock ${ }^{1}$ and Kian Fan Chung ${ }^{1}$

${ }^{1}$ Airways Diseases, National Heart and Lung Institute, Imperial College London, London, ${ }^{2}$ Dept of Biomedical Sciences, University of Wolverhampton, Wolverhampton, ${ }^{3}$ University of Exeter Medical School, Exeter, and ${ }^{5}$ Statistical Advisory Service, Imperial College London, London, UK. ${ }^{4}$ Dipartimento di Scienze Mediche, Centro Interdipartimentale per lo Studio delle Malattie Infiammatorie delle Vie Aeree e Patologie Fumo-correlate (CEMICEF), Sezione di Medicina Interna e Cardiorespiratoria, Università di Ferrara, Ferrara, Italy.

Correspondence: P.A. Kirkham, Dept of Biomedical Sciences, Faculty of Science and Engineering, University of Wolverhampton, Wulfruna Street, Wolverhampton, WV1 1LY, UK. Email: P.Kirkham@wlv.ac.uk

Received: July 302013 | Accepted after revision: Jan 042014 | First published online: Feb 132014

Conflict of interest: Disclosures can be found alongside the online version of this article at www.erj.ersjournals.com

Clinical trial: This study is registered at www.clinicaltrials.gov with identifier number NCT00241631.

\section{References}

1 Whiteman M, Winyard PG. Hydrogen sulfide and inflammation: the good, the bad, the ugly and the promising. Expert Rev Clin Pharmacol 2010; 4: 13-32.

2 Han W, Dong Z, Dimitropoulou C, et al. Hydrogen sulfide ameliorates tobacco smoke-induced oxidative stress and emphysema in mice. Antioxid Redox Signal 2011; 15: 2121-2134.

3 Perry MM, Hui CK, Whiteman M, et al. Hydrogen sulfide inhibits proliferation and release of IL-8 from human airway smooth muscle cells. Am J Respir Cell Mol Biol 2011; 45: 746-752.

Chen YH, Yao WZ, Geng B, et al. Endogenous hydrogen sulfide in patients with COPD. Chest 2005; 128: 3205-3211. Chen YH, Yao WZ, Ding YL, et al. Effect of theophylline on endogenous hydrogen sulfide production in patients with COPD. Pulm Pharmacol Ther 2008; 21: 40-46.

6 Saito J, Zhang Q, Hui C, et al. Sputum hydrogen sulfide as a novel biomarker of obstructive neutrophilic asthma. J Allergy Clin Immunol 2013; 131: 232-234.

7 Ford PA, Durham AL, Russell RE, et al. Treatment effects of low-dose theophylline combined with an inhaled corticosteroid in COPD. Chest 2010; 137: 1338-1344.

8 Whiteman M, Gooding KM, Whatmore JL, et al. Adiposity is a major determinant of plasma levels of the novel vasodilator hydrogen sulphide. Diabetologia 2010; 53: 1722-1726.

9 Kirkham P, Barnes PJ. Oxidative stress in COPD. Chest 2013; 144: 266-273.

10 Li SB, Tong XS, Wang XX, et al. Regulative mechanism of budesonide on endogenous hydrogen sulfide, cystathionine- $\gamma$-lyase and cystathionine- $\beta$-synthase system in asthmatic rats. Zhongguo Dang Dai Er Ke Za Zhi 2010; 12: 654-657. 